\title{
Profile of Head and Neck Cancer Patients at Department of Otorhinolaringology-Head and Neck Surgery Dr. Hasan Sadikin General Hospital Bandung
}

\author{
Inez Aulia Rakhmawulan, ${ }^{1}$ Yussy Afriani Dewi, ${ }^{2}$ Nursiah Nasution ${ }^{3}$ \\ ${ }^{1}$ Faculty of Medicine Universitas Padjadjaran, ${ }^{2}$ Department of Otorhinolaringology-Head and \\ Neck Surgery Faculty of Medicine Universitas Padjadjaran/Dr. Hasan Sadikin General Hospital \\ Bandung, ${ }^{3}$ Department of Anatomy and Cell Biology Faculty of Medicine Universitas Padjadjaran
}

\section{Abstract}

Background: Head and neck cancer is a health problem with a high mortality rate. Head and neck cancer are increasing and effect many individuals from diverse backgrounds. Usually patients come with advanced stages, therefore these conditions could lead to decrease their quality of life. Aim of this study was to describe the profile of head and neck cancer patients at the Otorhinolaringology-Head and Neck Surgery Department, Dr. Hasan Sadikin General Hospital Bandung.

Methods: A descriptive cross-sectional method was used from medical records of head neck cancer patients at Department of Otorhinolaringology-Head and Neck Surgery, Dr. Hasan Sadikin General Hospital Bandung from 2008 to 2012 that used the total sampling method.

Results: There were 665 patients included in this study, which men who participated were 388 and women were 277. Most of them were elementary educated (44.96\%), housewives (32.03\%), and those aged 46-55 years old (28.33\%). There were nasopharyngeal $(38.20 \%)$, sinonasal $(17.29 \%)$, larnyx $(13.08 \%)$, oropharnyx (6.32\%), thyroid gland (6.17\%), oral cavity $(3.91 \%)$, hypopharynx $(2.41 \%)$, and parotid gland $(2.26 \%)$ cancer. The major histopathological findings were undifferentiated carcinoma $(45.41 \%)$ and squamous cell carcinoma (22.26\%), those were presented with stage I (7.4\%), II (13.5\%), III (24.4\%), and IV (54.7\%).

Conclusions: Nasopharyngeal carcinoma was the most predominant cases which majority were presented in advanced stage and major histopathology features was undifferentiated carcinoma, while demografic characteristic mostly were in middle aged and older, men with low education background. [AMJ.2015;2(4):474-9]

Keywords: Head and neck cancer, nasopharyngeal carcinoma, otorhinolaringology

\section{Introduction}

Head and neck cancer is the fifth most common cancer worldwide. ${ }^{1}$ New cases of head and neck cancer are reported approximately 650,000 cases worldwide per year with a mortality rate of 350,000 cases per year. ${ }^{2}$ It is increasing in incidence over the past three decades. ${ }^{3}$ The term of head and neck cancer is usually used to describe all carcinoma arising from upper aerodigestive tract such as sinonasal tract, oral cavity, pharynx, and larnyx, usually reffered to squamous cell carcinoma due to the predominant histopathology. ${ }^{3}$ Risk factors for this illness include a history of smoking, passive smoker, exposure to carcinogens, diet, oral hygiene, infectious diseases such as Human Papilloma Virus (HPV), and Epstein Barr Virus (EBV), family history, and alcohol consumption. ${ }^{4,5}$ Age, gender, race, and social economic status are also important in determining the risk of head and neck cancer. ${ }^{6}$

Head neck cancer is an important health problem. This kind of cancer is usually three to five times more prevalent among men than women. In one study in Brazil ${ }^{7}$ from 427 patients, the most frequent tumor site in our series is the oral cavity (35.37\%). A high frequency of head and neck cancer cases is diagnosed at an advanced stage, and the most representative histological type is the squamous cell carcinoma ( $96.7 \%$ of cases). The prognosis for head neck cancer depends

Correspondence: Inez Aulia Rakhmawulan, Faculty of Medicine, Universitas Padjadjaran, Jalan Raya BandungSumedang Km.21, Jatinangor, Sumedang, Indonesia, Phone: +62811121291, Email: inez.rakhmawulan@gmail.com 
on the stage of the illness. ${ }^{6}$ Patients suffering from early stages of this cancer have a better quality of life post treatment compared to advanced stage patients. Cancer patients will never regain a normal standard of health.8 If this fact does not receive appropriate attention, then an increase in the incidence of head neck cancer is possible. This study was conducted to determine the profile of head neck cancer patients specifically age, gender, occupation, staging, primary site and histopathological finding at the Department of Otorhinolaringology-Head and Neck Surgery, Dr. Hasan Sadikin General Hospital Bandung from 2008 to 2012

\section{Methods}

This study was carried out from August to October 2013 at the Department of Otorhinolaringology-Head and Neck, Dr. Hasan Sadikin General Hospital Bandung used the cross sectional descriptive method. The population was all the head neck cancer patients who were hospitalized or received outpatient treatment. Medical records from study subjects were served as the secondary data. A total sampling method was used to collect the sample. This study was approved by the Health Research Ethics Committee Faculty of Medicine, Universitas Padjadjaran, and Dr. Hasan Sadikin General Hospital.

The samples were all the subjects that had the complete data. The inclusion criteria were the medical records that encompass all the variables analyzed such as age, sex, job, education, primary site, histopathological findings, and stage of cancer. The data were derived with descriptive statistics, using frequency and percentage calculations by the Excel software (Version 2011). The results of the study were illustrated in tables.

Head and neck cancer was chosen based on clinical diagnosis, according to the anatomical site such as nasopharynx, larynx, sinonasal, oropharynx, hypopharynx, oral cavity, thyroid gland, parotid gland, and neck based on the American Joint Committee on Cancer (AJCC) of 2010. Hodgkin lymphoma and non-Hodgkin lymphoma cases are also included. ${ }^{9}$

Age was grouped into $0-5,5-11,12-16$, $17-25,26-35,36-45,46-55,56-65$, and $>65$ years old.

Furthermore, education was grouped into uneducated, elementary school, middle school, and university. Occupation was divided into unemployed, laborer, farmer, houswife, government worker, private worker, student, and others. Histopathological findings were classified based on World Health Organization Classification of Tumor in 2005.10 Tumor staging was grouped by the location and by the TNM criteria based on AJCC 2010 to stage I, II, III, IV. ${ }^{9}$

\section{Results}

During the study period, there were 1,006 head and neck cancer patients in the Otorhinolaringology-Head and Neck Surgery

\section{Table 1 Characteristics of Head and Neck} Cancer Patients

\begin{tabular}{|c|c|c|}
\hline Variables & $n=665$ & $\%$ \\
\hline \multicolumn{3}{|l|}{ Education } \\
\hline Elementary School & 299 & 45.0 \\
\hline High School & 175 & 26.3 \\
\hline Middle School & 111 & 16.7 \\
\hline Uneducated & 40 & 6.0 \\
\hline University & 40 & 6.0 \\
\hline \multicolumn{3}{|l|}{ Occupation } \\
\hline Housewife & 213 & 32.0 \\
\hline Laborer & 98 & 14.7 \\
\hline Unemployed & 97 & 14.6 \\
\hline Entrepreneur & 85 & 12.8 \\
\hline Private Worker & 61 & 9.2 \\
\hline Farmer & 46 & 6.9 \\
\hline Government Worker & 29 & 4.4 \\
\hline Student & 20 & 3.0 \\
\hline Retired & 9 & 1.4 \\
\hline Other & 7 & 1.1 \\
\hline \multicolumn{3}{|l|}{ Age (Years Old) } \\
\hline $46-55$ & 197 & 29.6 \\
\hline $36-45$ & 131 & 19.7 \\
\hline $56-65$ & 127 & 19.1 \\
\hline$>65$ & 96 & 14.4 \\
\hline $26-35$ & 68 & 10.2 \\
\hline $17-25$ & 37 & 5.6 \\
\hline $12-16$ & 8 & 1.2 \\
\hline $5-11$ & 1 & 0.2 \\
\hline Median age & \multicolumn{2}{|c|}{$46-55$} \\
\hline Mode of Age & \multicolumn{2}{|c|}{$46-55$} \\
\hline Mean \pm std. dev. Age & \multicolumn{2}{|c|}{$49.4 \pm 14.6$} \\
\hline Age Range & \multicolumn{2}{|c|}{$11-87$} \\
\hline
\end{tabular}


Table 2 Distribution of Patients according to Gender and Cancer Sites

\begin{tabular}{lcccc}
\hline \multirow{2}{*}{ Subsites } & \multicolumn{2}{c}{ Males } & \multicolumn{2}{c}{ Females } \\
\cline { 2 - 5 } & $\mathbf{n = 3 8 8}$ & $\mathbf{\%}$ & $\mathbf{n = 2 7 7}$ & $\mathbf{\%}$ \\
\hline Nasopharynx & 156 & 61.4 & 98 & 38.6 \\
Sinonasal & 56 & 48.7 & 59 & 51.3 \\
Larynx & 79 & 90.8 & 8 & 9.2 \\
Non Hodgkin Malignant Lymphoma & 37 & 59.7 & 25 & 40.3 \\
Oropharynx & 25 & 59.5 & 17 & 40.5 \\
Thyroid Gland & 8 & 19.5 & 33 & 80.5 \\
Oral Cavity & 13 & 50.0 & 13 & 50.0 \\
Hypopharinx & 7 & 43.8 & 9 & 56.3 \\
Parotid Gland & 2 & 13.3 & 13 & 13.0 \\
Neck & 5 & 71.4 & 2 & 28.6 \\
\hline
\end{tabular}

Department, Dr. Hasan Sadikin General Hospital Bandung from 2008 to 2012. Only 665 were included due to the completeness of data in medical records, which 341 were excluded in this study.
The predominant education level was elementary school. Based on the background, housewives were highly affected (32.0\%). Patients in the group of 46-55 years old were predominantly found, accounted as 197

Table 3 Histopathological Findings of Head and Neck Cancer

\begin{tabular}{lcc}
\hline \multicolumn{1}{c}{ Histopathology } & n & (\%) \\
\hline Undifferentiated Carcinoma & 302 & 45.4 \\
Squamous Cell Carcinoma & 203 & 30.5 \\
Non Hodgkin Malignant Lymphoma & 62 & 9.3 \\
Papillary Carcinoma & 19 & 2.9 \\
Folicullar Neoplasm? Non malignant? & 18 & 2.7 \\
Adenoid Cystic Carcinoma & 14 & 2.1 \\
Adenocarcinoma & 11 & 1.7 \\
Pleomorphic Adenoma & 10 & 1.5 \\
Mucoepidermoid Carcinoma & 6 & 0.9 \\
Transitional Cell Carcinoma & 6 & 0.9 \\
Anaplastic Carcinoma & 3 & 0.5 \\
Acinic Cell Carcinoma & 2 & 0.3 \\
Angiosarcoma & 2 & 0.3 \\
Adenosquamous Cell Carcinoma & 1 & 0.2 \\
Basal Cell Carcinoma & 1 & 0.2 \\
Hemangioperisitoma & 1 & 0.2 \\
Melanoma Maligna & 1 & 0.2 \\
Myxofibrosarcoma & 1 & 0.2 \\
Rabdomiosarcoma & 1 & 0.2 \\
Spindle Cell Carcinoma & 1 & 065 \\
Total & 1 & 0.2 \\
\hline
\end{tabular}


Inez Aulia Rakhmawulan, Yussy Afriani Dewi, Nursiah Nasution: Profile of Head and Neck Cancer Patients at 477 Department of Otorhinolaringology-Head and Neck Surgery Dr. Hasan Sadikin General Hospital Bandung

Table 4 Stages of Head and Neck Cancer

\begin{tabular}{lcc}
\hline \multicolumn{1}{c}{ Stage } & n & \% \\
\hline IV & 364 & 54.7 \\
III & 162 & 24.4 \\
II & 90 & 13.5 \\
I & 49 & 7.4 \\
Total & 665 & 100 \\
\hline
\end{tabular}

patients (29.6\%) (Table 1).

There were more of male patients than female, with the ratio of $1.4: 1$. The predominant of head and neck clinical diagnosis were asopharyngeal carcinoma (38.2\%), followed by sinonasal $(17.3 \%)$, and larynx $(13.1 \%)$ (Table 2).

The majority of histological findings found in this study were undifferentiated carcinoma in 302 patients ( $45.4 \%$ ), followed by squamous cell carcinoma in 148 patients $(22.3 \%)$ (Table 3 ). There were more of advanced stage patients than the early stage's (Table 4).

\section{Discussions}

A tumor is an abnormal growth of tissue, where cells multiply excessively and in an uncontrolled manner. There are two kinds of tumors, which are benign and malignant. A tumor is classified as malignant when the growth infiltrates the surrounding tissue and starts to metastasize , which is known as a carcinoma. ${ }^{11}$

The term of head and neck cancer is used to describe all types of cancers stemming from the upper aerodigestive tract, such as sinonasal tract, the oral cavity, the pharynx, or the larynx. It is normally reffered to squamous cell carcinoma, because it is the most common histopathology. ${ }^{3}$

Out of the 15,138 patients in the Department of Otorhinolaringology-Head and Neck Surgery, Dr. Hasan Sadikin General Hospital Bandung, there were 1,006 patients of head and neck cancer from 2008 to 2012 . The number of head and neck cancer cases was higher than the 427 cases in University Hospital of Northwestern São Paulo state, from 2000 to 2005. ${ }^{7}$ From the 1,006 patients, only 665 patients were included in this study because their medical records had all the variables needed. The ratio of males to females was 1.4 to 1 . A study by Kim et al. ${ }^{6}$ also stated that the incidence of head and neck cancer is three-fold higher in men than in women. This is probably caused by the fact that men have a higher tendency to smoke ciggaretes and consume alcohol than women. A study by Dahlstrom et al. ${ }^{12}$ also supports that smoking and drinking alcohol, which are risk factors for head and neck cancer, are behaviors observed more frequently in men (79.9\%) than in women.

In this study, the predominant head and neck cancer type was nasopharyngeal carcinoma $(38.2 \%)$, followed by sinonasal cancer $(17.3 \%)$, and laringeal cancer $(13.1 \%)$. The percentage of nasopharingeal carcinoma cases were significantly higher compared to the other head and neck cancer types. A literature by Munir et al. ${ }^{13}$ studied in Indonesia, also found that almost $60 \%$ of head and neck cancer to be nasopharyngeal carcinoma, which $18 \%$ to be sinonasal carcinoma, and $16 \%$ to be laryngeal, while other types of cancer have very low percentages. The etiology of this cancer is probably due to the infection of Epstein barr virus, and is influenced by lifestyle, bad dietary habits, and genetic factors. Lutzky et al. ${ }^{14}$ reported that in 2000 , more than $80 \%$ of cases of nasopharyngeal carcinoma in Southeast Asia are new. Influencing risk factors for pathogenesis of nasopharingeal carcinoma include childhood diet, for instance, a diet of preserved meats and Cantonese-style salted fish known containing carcinogenic nitrosamines. Other environmental factors associated with the development of nasopharingeal carcinoma include smoking, alcohol, and Chinese herbal medication. ${ }^{14}$

Most of the patients were not highly educated, which 299 patients were only elementary school graduates $(45 \%)$ and 111 patients were middle school graduates $(16.7 \%)$. Findings suggest that patients lacking higher education were more likely uninformed about head and neck cancer. People without higher education tended to have a lower socioeconomic status, which may affect their lifestyle; for examples, they might have a bad diet and bad oral hygiene. Previous studies by the 2009 International Head and Neck Cancer Epidemiology (INHANCE) discovered that $38.7 \%$ of the 12,282 total cases have only a middle school education. ${ }^{15}$

Although this cancer predominated in males than in females, the majority of the females who studied were housewives (32\%), while male patients had various employments. A study in Brazil reported that there are more rural workers among males, and more housewives among females. ${ }^{7}$ This suggests that the women might acquire the cancer from mutlifactorial cause such as genetics, exposure to carcinogenic agent, or they were exposed 
as passive smoker. It is also possibly due to changes in smoking and alcohol drinking habits in females. ${ }^{7,16} \mathrm{Kim}$ et al. ${ }^{6}$ also discovered that of the many studies from high and low income countries, patients with low socioeconomic status and a low level of education have a higher risk of cancer, especially oral cancer.

The highest instances of head and neck cancer cases was among middle aged adults (46-55 years old), as many as 285 patients $(29.6 \%)$ fell in this category, the median age being 46-55 years old, with a range of 11-87 years old. The study conducted in Egypt by Tawfik et al. ${ }^{17}$ also reported that the median age is $46-55$ years old and the cancer is more common among people 46-55 years old and older. This study showed that a long exposure period to carcinogens, virus, DNA genes, and accumulation of mutation increased the risk factor for cancer. Syrigos et al. ${ }^{2}$ also found that the eldery may be effected by high exposure to risk factors over a long period of time, or by an accumulation of mutations, decrease in DNA repair efficiency, and a weakening immune system.

The majority, 302 patients (45.4\%), of histological findings were classified as undifferentiated carcinoma, while 148 patients $(22.3 \%)$ were classified as having squamous cell carcinoma. Nevertheless, previous research studies by Goon et al. ${ }^{3}$ Kim et al. ${ }^{6}$ and Syrigos et al. ${ }^{2}$ reported that $90 \%$ of head and neck cancer malignancies are squamous cell carcinoma. This finding is commonly linked to the infection of Human Papilloma Virus (HPV). ${ }^{2,3,6,13}$ Undifferentiated carcinoma is usually found in nasopharingeal carcinoma and sinonasal cancer, which often relate to an Epstein Barr Virus (EBV) infection characterized by rapid metastasis and causing death. ${ }^{5,10,18}$

The majority of patients were diagnosed at advanced stage of cancer (stage III and IV). According to Ruback et al. ${ }^{19}$ and Santos et al. ${ }^{20}$ a high proportion of cancer patients is only diagnosed at advanced stage, and demonstrates the difficulty in obtaining an early diagnosis. This is probably due to lack of patients' knowledge about head and neck cancer, as the symptoms are not incapacitating in early stages, and the hospital fee is either too expensive or they choose alternative medicine instead of going to see a doctor. The prognosis of head and neck cancer is based on patient's stage of cancer when it is first diagnosed. During the early stages, patients have a $60-95 \%$ chance of being healed by local treatment only, while patients in the advanced stages have over a $50 \%$ chance of recurrence or metastasisation of the cancer. ${ }^{6}$

Limitation of this study is the incomplete and missing data, also data were only obtained from one hospital, most of the patients were reffered from other hospitals. This might be seen as an iceberg phenomenon because it could only be seen from the patients who came to Dr. Hasan Sadikin General Hospital instead of the total population at risk. Further studies can be conducted with other variables such as address, race, chief complain, therapy, and history of smoking or to corelate the risk factors with head and neck cancer and to assess their quality of life.

In conclusion, head and neck cancer occurred more commonly in males. It predominates in middle aged (46-55 years old) and older. A high proportion of head and neck cancer was presented in people with a low level of education specifically elementary school educated and low level of socioeconomic status. Nasopharingeal carcinoma is found to be the most common type of head and neck cancer. The majority of patients are already on the advanced stage of cancer. The patients are found to have undifferentiated carcinoma as their predominant histopathological finding.

Head and neck cancer can affect people from various backgrounds, which are education and prevention needed in the communities to decrease the incidence of head and neck cancer. It is suggested to do early detection on patients who have characteristics with a high incidence, by disseminating the study result to first-line health workers and educate them to achieve early detection of the disease, so the patients can get a proper early treatment, disability restriction and other prevention. Usually patients come with advanced stages, beside of treatment options, which palliative care is also needed to improve their quality of life

\section{References}

1. Ferreira M, Souza JAD, Cohen E. Role of molecular markers in the management of head and neck cancers. Curr Opin in Oncol. 2011;23(3):259-64.

2. Syrigos KN, Karachalios D, Karapanagiotou EM, Nutting CM, Manolopoulos L, Harrington KJ. Head and neck cancer in the elderly: an overview on the treatment modalities. Cancer Treat Rev. 2009;35(3):237-45.

3. Goon PK, Stanley MA, Ebmeyer Jr, Steinsträsser L, Upile T, Jerjes W, et al. 
HPV \& head and neck cancer: a descriptive update. Head Neck Oncol. 2009;1:36.

4. Hassan MA, Lund VJ, Howard DJ, Sacker AA. Are the demographics for squamous cell cancer in the head and neck changing in the United Kingdom? J Laryngol Otol. 2007;121(2):154-7.

5. Haddad RI, Shin DM. Recent Advances in Head and Neck Cancer. N Engl J Med. 2008;359(11):1143-54.

6. Kim L, King T, Agulnik M. Head and Neck Cancer: Changing Epidemiology and Public Health Implications. Oncology. 2010;24(10): 915-9.

7. Alvarenga LdM, Ruiz MT, Bertelli ECO, Ruback MJC, Maniglia JV, et al. Epidemiologic evaluation of head and neck patients in a university hospital of Northwestern São Paulo State. Braz J Otorhinolaryngol. 2008;74(1):68-73.

8. Chaukar DA, Walvekar RR, Das AK, Deshpande MS, Pai PS, Chaturvedi P, et al. Quality of life in head and neck cancer survivors: a cross-sectional survey. Am J Otolaryngol. 2009;30(3):265-70.

9. Deschler DG, Day T, editors. Pocket guide to neck dissection classification and tnm staging of head and neck cancer and neck dissection classification. 3rd Edition. Alexandria: American Academy of Otolaryngology-Head and Neck Surgery Foundation, Inc.; 2008. p. 16-28

10. WHO. Pathology and genetics of head and neck tumours. Lyon: IARC Press; 2005.

11. Dorland NW. Dorland's pocket medical dictionary. 28th ed. Philadelphia: W.B. Saunders; 2009.; p. 875-6.

12. Dahlstrom KR, Little JA, Zafereo ME, Lung M, Wei Q Sturgis EM. Squamous cell carcinoma of the head and neck in never smoker-never drinkers: a descriptive epidemiologic study. Head Neck. 2008;30(1):75-84

13. Munir M. Keganasan di bidang telinga hidung tenggorok. In: Soepardi EA, Iskandar N, Bashiruddin J, Restuti RD, editors. Buku ajar ilmu kesehatan telinga hidung tenggorok kepala \& leher. 6th ed. Jakarta: Balai Penerbit FKUI; 2007. p. 132

14. Lutzky VP, Moss DJ, Chin D, Coman WB, Parsons PG, Boyle GM. Biomarkers for cancers of the head and neck. Clin Med Insights Ear Nose Throat. 2008;1:5-15.

15. Hashibe M, Brennan P, Chuang S-c, Boccia $\mathrm{S}$, Castellsague $\mathrm{X}$, Chen $\mathrm{C}$, et al. Interaction between tobacco and alcohol use and the risk of head and neck cancer: pooled analysis in the international head and neck cancer epidemiology consortium. Cancer Epidemiol Biomarkers Prev. 2009;18(2):541-50.

16. Durazzo MD, de Araujo CEN, Neto JdSB, Potenza AdS, Potenza AdS, Costa P, et al. Clinical and epidemiological features of oral cancer in a medical school teaching hospital from 1994 to 2002: increasing incidence in women, predominance of advanced local disease, and low incidence of neck metastases. Clinics (Sao Paulo). 2005;60(4):293-8.

17. Tawfik HM, El-Maqsoud NMRA, Hak BHAA, El-Sherbiny YM. Head and neck squamous cell carcinoma: mismatch repair immunohistochemistry and promoter hypermethylation of hMLH1 gene. Am J Otolaryngol. 2010;32(6):528-36.

18. Powles T, Powles J, Nelson M, Sandison A, Peston D. Head and neck cancer in patients with human immunodeficiency virus infection: incidence, outcome and association with Epstein-Barr virus. J Laryngol Otol. 2004;118(3):207-12.

19. Ruback McJC, Galbiatti ALv, Arantes LMRB, Marucci GH, RussoI A, Ruiz-CintraII MT, et al. Clinical and epidemiological characteristics of patients in the head and neck surgery department of a university hospital. Rev Assoc Med Bras. 2012;130(5):307-13.

20. Santos LC, Cangussu MC, Batista Ode M, Santos JP. Oral cancer: Population sample of the State of Alagoas at a Reference Hospital. Braz J Otorhinolaryngol. 2009;75(4):524-9. 